\title{
Anxiety is associated with undesirable eating behaviors in university students during the COVID- 19 pandemic
}

Kathryn E Coakley ( $\sim$ kcoakley@unm.edu )

University of New Mexico College of Education https://orcid.org/0000-0002-2887-3546

Huyen Le

University of New Mexico College of Education

Spirit Rae Silva

University of New Mexico College of Education

Aspen Wilks

University of New Mexico College of Education

\section{Research}

Keywords: Anxiety, mental health, eating behaviors, eating attitudes, undergraduate students, graduate students, COVID-19

Posted Date: January 19th, 2021

DOI: https://doi.org/10.21203/rs.3.rs-148637/v1

License: (c) (i) This work is licensed under a Creative Commons Attribution 4.0 International License. Read Full License 


\section{Abstract \\ Background}

COVID-19 has impacted mental health globally, however, relationships between anxiety and eating behaviors during the pandemic have not been explored. This study evaluated anxiety, eating attitudes and behaviors, and associations between anxiety and eating behaviors in students at a large public University in the United States during the COVID-19 pandemic.

\section{Methods}

Current undergraduate and graduate/professional students completed a cross-sectional survey in fall 2020. Demographic information, indicators of anxiety in the past two weeks assessed by the Generalized Anxiety Disorder Screener (GAD-7), and eating behaviors assessed by the Adult Eating Behavior Questionnaire (AEBQ) were evaluated. A score $\geq 10$ on the GAD-7 indicated anxiety ( $\geq 15$ indicated severe anxiety). Eating behaviors were reported via Likert scale and combined into eight AEBQ subscales; subscale mean and standard deviation were reported. Differences in mean AEBQ subscale scores were examined between participants with and without anxiety via Mann-Whitney $U$ tests. Multivariate linear regression was utilized to examine associations between GAD-7 score and individual AEBQ subscale scores, adjusting for age, gender, race/ethnicity, and student status.

\section{Results}

The final sample included 1243 students (57\% undergraduates). In the full sample, 51.9\% experienced anxiety in the past two weeks; $24.6 \%$ had severe anxiety. Subgroups with the highest prevalence of anxiety included non-cisgender participants (73.6\%), the youngest age group [18-20 years of age (62\%)], undergraduate students (60.7\%), and Hispanic/Latino participants (57.5\%). Participants with anxiety had significantly lower AEBQ scores for enjoyment of food and significantly higher scores for emotional over and under-eating, food fussiness, food and satiety responsiveness, and hunger than those with no anxiety $(p<0.01)$. In adjusted analyses, GAD-7 score was significantly and positively associated with hunger, food responsiveness, emotional over-eating, satiety responsiveness, and food fussiness and negatively associated with enjoyment of food.

\section{Conclusions}

The prevalence of anxiety is overwhelming in undergraduate and graduate/professional students amidst the COVID-19 pandemic. Eating behaviors differ significantly in those with anxiety; increasing anxiety severity was associated with undesirable eating behaviors including hunger and emotional over-eating. Universities and health professionals must consider strategies to address anxiety, particularly in younger 
students, non-cis-gender students, and across race/ethnicities keeping in mind associations between anxiety and eating behaviors.

\section{Background}

The novel coronavirus 2019 (COVID-19) pandemic has impacted mental health around the world (1). Fear of contracting the virus combined with the implementation of public health measures including social distancing and stay-at-home orders can cause significant stress which may induce or exacerbate anxiety (2). By June 2020 , over $40 \%$ of the general population in the United States reported one or more adverse mental or behavioral health symptom (3). Prior to the COVID-19 pandemic, anxiety disorders were the most common mental illness in the United States, affecting $18.1 \%$ of the population 18 years and older (4). Since the start of the COVID-19 pandemic, anxiety is now evident in more than one in four U.S. adults (3). Rising prevalence of anxiety is not unique to the United States; symptoms of anxiety are now present in approximately $6.33-50.9 \%$ of the general population worldwide (5).

In young adults, prevalence of anxiety during the pandemic is even higher. The Centers for Disease Control and Prevention (CDC) reported $49 \%$ of young adults 18-24 years of age in the United States had anxiety by June 2020 compared to $25.5 \%$ of the general population (3). Anxiety is a growing concern in young adult university students in particular, as institutions of higher education moved to remote and online delivery in response to the pandemic $(6,7)$. Worldwide, estimates of the prevalence of anxiety in university students range from 25\% in China in early 2020 (8) and 27.5\% in France in April 2020 (9) to $38.5 \%$ in the United States (10) and 42.9\% in Bangladesh in May 2020 (11). More current estimates of the burden of anxiety in students in fall 2020, as many Universities continue remote or hybrid education models, have not yet been reported.

Anxiety impacts physical health, lifestyle, and academic performance and during the COVID-19 pandemic, university students report difficultly coping with stress adequately $(10,12)$. Stress is a known trigger for undereating and overeating (13) and even in non-pandemic times, the relationship between anxiety and eating behaviors and attitudes is documented $(14,15)$. In college students, anxiety and depression are associated with changes in food choices and total caloric intake (16) and anxiety is associated with food insecurity (17). College students are already at-risk for disordered eating including caloric restriction, binge eating, and compensatory behaviors $(18,19)$. Disordered eating, even in the absence of a diagnosed eating disorder is associated with body weight perception and dissatisfaction, depression and perceived stress, and risk for underweight and overweight/obesity $(19,20)$. In the United States, adults with self-reported eating disorders have been particularly impacted by the COVID-19 pandemic, reporting increased restrictive behaviors, fears regarding finding food, and increased urges to binge and actual binge eating episodes (21). In undergraduate students, public health measures including quarantining have also been associated with concerns about body weight and shape and eating habits (22). In summary, the COVID-19 pandemic has created an environment conducive to stress, anxiety, and potentially undesirable eating behaviors. 
Despite the high prevalence of anxiety worldwide, there is limited evidence on the burden of anxiety in university students in late 2020, or the relationship between anxiety and eating attitudes and behaviors during a global pandemic. This study aimed to examine the prevalence of anxiety in university students, including by demographic groups, amidst the COVID-19 pandemic and to examine associations between anxiety and eating attitudes and behaviors.

\section{Methods}

A cross-sectional survey-based study was conducted in fall 2020, during a second wave of the COVID-19 pandemic in the United States. The authors followed the STROBE-nut Statement to report results (23).

\section{Participants and Recruitment}

Participants were currently enrolled undergraduate or graduate/professional students at a large, public University in the southwest region of the United States. All participants were at least 18 years of age. Participants were recruited for four weeks from September to October 2020 during a second wave of COVID-19 cases in the University's state. A recruitment email was distributed to all undergraduate and graduate students currently enrolled in each of the University's Colleges; one College declined to distribute the email. The recruitment email was also sent via the University's Graduate and Professional Student listserv. Participants provided consent by starting the survey and no consent signature was required. At the end of the survey, students could choose to provide their email address to enter a drawing for a \$20 gift card incentive. Five email addresses were randomly selected to receive $\$ 20$ gift cards after data were collected. The study was approved by the University's Office of the Institutional Review Board.

\section{Data Collection}

Data were collected via Opinio, an online survey tool approved for research. The survey included two screening questions assessing the potential participant's age ( $\geq 18$ years) and confirming current enrollment as a full-time or part-time undergraduate or graduate student at the University. The survey then included four demographic questions (gender, age, race/ethnicity, and academic status); the seven-item Generalized Anxiety Disorder Scale (GAD-7), a validated measure of anxiety in the past two weeks in the general population $(24,25)$; and the 35-item Adult Eating Behavior Questionnaire (AEBQ), a validated measure of appetitive traits and eating behaviors $(26,27)$. The AEBQ includes eight subscales divided into four food approach behaviors (hunger, food responsiveness, emotional over-eating, and enjoyment of food) and four food avoidance behaviors (satiety responsiveness, emotional under-eating, food fussiness, and slowness in eating) (27). Food responsiveness is defined as the tendency to eat (or eat more) in response to food cues including the sight and smell of food (28). Satiety responsiveness is defined as the capacity to adjust eating and food intake in response to feelings of satiety and fullness (28).

\section{Data Analysis}


A power analysis was not conducted due to the exploratory nature of the study. All participants who completed the GAD-7 were included in data analyses. Since all survey questions were optional, some demographic data were missing and were reported as such. All data analyses were performed using Statistical Analysis Software (SAS; version 9.4; SAS Institute, Cary, NC, USA).

Demographic data were presented with descriptive statistics. Continuous variables including age, GAD-7 score, and AEBQ subscale scores were assessed for normality using the Shapiro-Wilk test. GAD-7 score ranges from 0 to 21 and, per standard guidelines, was dichotomized to indicative of anxiety (score $\geq 10$ ) or not indicative of anxiety (score < 10) (25). GAD-7 scores were also used to categorize the severity of anxiety: mild (score of 5-9), moderate (score of 10-14), or severe (score $\geq 15)$ (25). The AEBQ was scored according to standard guidelines by reverse scoring four of the 35 questions and then calculating the average of Likert scale responses (scale 1-5) for questions included in each of the eight subscales.

The prevalence of anxiety, including by severity, was calculated for the full sample and by demographic subgroups including age category, gender, race/ethnicity, and student status (undergraduate or graduate/professional). Differences in the prevalence of anxiety severity (no anxiety, mild anxiety, moderate anxiety, severe anxiety) within demographic groups were assessed using Chi-square tests. Differences in mean AEBQ subscale scores were compared between participants with symptoms of anxiety versus those with no symptoms of anxiety using Mann-Whitney U tests. Spearman's correlation coefficients were calculated between individual AEBQ indicators and GAD-7 score. Multivariate linear regression was utilized to examine the association between GAD-7 score and individual AEBQ indicators, adjusting for age (continuous), gender, race/ethnicity, and student status. A $p<0.05$ was considered statistically significant for all tests.

\section{Results}

Eight of the nine Colleges at the University and the Graduate and Professional Student Association sent the recruitment email to all currently enrolled undergraduate and graduate/professional students in September 2020. The number of students who received the recruitment email was not documented; however, 1,367 students started the survey. Of those, 17 (1.2\%) were excluded based on responses to the two screening questions and an additional 107 (7.8\%) were excluded for not completing the GAD-7. Thus, $1243(90.9 \%)$ participants were included in the final analysis. 
Table 1

Demographic characteristics of study participants $(n=1243)$

\begin{tabular}{|c|c|c|}
\hline Demographics $^{a}$ & $\mathbf{n}$ & $\%$ \\
\hline \multicolumn{3}{|l|}{ Age (years) } \\
\hline $18-20$ & 353 & 29.5 \\
\hline $21-24$ & 326 & 27.2 \\
\hline $25-30$ & 205 & 17.1 \\
\hline$>30$ & 314 & 26.2 \\
\hline \multicolumn{3}{|l|}{ Gender } \\
\hline Female & 909 & 73.1 \\
\hline Male & 281 & 22.6 \\
\hline Non-cisgender & 53 & 4.3 \\
\hline \multicolumn{3}{|l|}{ Race/Ethnicity } \\
\hline American Indian or Alaskan Native & 60 & 4.9 \\
\hline Asian & 99 & 8.0 \\
\hline Black or African American & 27 & 2.2 \\
\hline Hispanic/Latino & 239 & 19.3 \\
\hline White & 732 & 59.2 \\
\hline More than one race/ethnicity or other & 79 & 6.4 \\
\hline \multicolumn{3}{|l|}{ Student Status } \\
\hline Undergraduate & 702 & 57.0 \\
\hline Graduate/Professional & 530 & 43.0 \\
\hline \multicolumn{3}{|l|}{ Anxiety Severity (GAD-7 score) } \\
\hline No Anxiety $(<5)$ & 238 & 19.2 \\
\hline Mild Anxiety (5-9) & 360 & 29.0 \\
\hline Moderate Anxiety (10-14) & 339 & 27.3 \\
\hline Severe Anxiety $(\geq 15)$ & 306 & 24.6 \\
\hline
\end{tabular}

aAge missing for 45 participants; race/ethnicity missing for 7 participants; student status missing for 11 participants 
Demographic characteristics of the study sample are presented in Table 1. The mean age of participants was $26.5 \pm 9.2$ years (range $18-82)$. The majority were female $(n=909 ; 73.1 \%)$, white $(n=732 ; 59.2 \%)$ or Hispanic/Latino ( $n=239 ; 19.3 \%)$, and undergraduate students $(n=702 ; 57 \%)$. The study sample differed from the general population of the University in fall 2020 , with an overrepresentation of females $(73.1 \%$ versus $57.4 \%$ ) and white students $(59.2 \%$ versus $33.3 \%$ ) and an underrepresentation of undergraduate students (57\% versus $70.9 \%$ ). The study sample did, however, accurately represent the University's composition of American Indian/Alaskan Native and Black/African American students. Mean age in this study (26.5 years) was comparable to the University's overall average of 25.7 years, reflecting the large population of non-traditional students.

In the full sample, the mean GAD-7 score was 10.1 \pm 5.6 . GAD-7 score was not normally distributed ( $p<$ 0.05). Over half of participants $(n=645 ; 51.9 \%)$ experienced anxiety in the past two weeks based on a GAD-7 score of 10 or more. In the full sample, $29 \%$ had mild anxiety, $27.3 \%$ had moderate anxiety, and $24.6 \%$ had severe anxiety. Nearly $90 \%$ of participants indicated symptoms of anxiety made it somewhat difficult (54.9\%), very difficult (22.2\%), or extremely difficult (10.9\%) to do work, take care of things at home, or get along with other people. The prevalence of anxiety differed significantly by age category, gender, and level of education $(p<0.01)$ but not by race/ethnicity $(p=0.13)$ (Table 2$)$. The youngest age category (18-20 years of age) had the highest prevalence of anxiety (62\%) including moderate anxiety $(33.7 \%)$ and severe anxiety (28.3\%) compared to older age groups. The oldest age category (>30 years of age) had the lowest prevalence anxiety (39.8\%) including moderate anxiety $(20.4 \%)$ and severe anxiety (19.4\%). Non-cisgender participants, including transgender, gender fluid, non-binary, and other-gendered participants, had the highest prevalence of anxiety (73.6\%) including moderate (34\%) and severe anxiety (39.6\%) compared to females and males. Male participants had the lowest prevalence of anxiety $(n=111$; $39.5 \%)$. 
Table 2

Prevalence of anxiety by severity in university students by demographic characteristics

\begin{tabular}{|c|c|c|c|c|c|c|c|c|c|}
\hline & \multicolumn{2}{|c|}{$\begin{array}{l}\text { Anxiety } \\
\text { (GAD-7 } \geq \\
\text { 10) }\end{array}$} & \multicolumn{2}{|c|}{$\begin{array}{l}\text { Mild Anxiety } \\
\text { (GAD-7 score } \\
5-9)\end{array}$} & \multicolumn{2}{|c|}{$\begin{array}{l}\text { Moderate Anxiety } \\
\text { (GAD-7 score 10- } \\
\text { 14) }\end{array}$} & \multicolumn{2}{|c|}{$\begin{array}{l}\text { Severe Anxiety } \\
\text { (GAD-7 score } \geq \\
\text { 15) }\end{array}$} & \multirow[b]{2}{*}{$p^{\mathrm{a}}$} \\
\hline & $\mathrm{N}$ & $\%$ & $\mathrm{~N}$ & $\%$ & $\mathrm{n}$ & $\%$ & $\mathrm{n}$ & $\%$ & \\
\hline Full Sample & 645 & 51.9 & 360 & 29.0 & 339 & 27.3 & 306 & 24.6 & \\
\hline Age (years) & & & & & & & & & $<.01$ \\
\hline $18-20$ & 219 & 62.0 & 82 & 23.2 & 119 & 33.7 & 100 & 28.3 & \\
\hline $21-24$ & 174 & 53.4 & 102 & 31.3 & 91 & 27.9 & 83 & 25.5 & \\
\hline $25-30$ & 105 & 51.2 & 62 & 30.2 & 56 & 27.3 & 49 & 23.9 & \\
\hline$>30$ & 125 & 39.8 & 101 & 32.2 & 64 & 20.4 & 61 & 19.4 & \\
\hline Gender & & & & & & & & & $<.01$ \\
\hline Female & 495 & 54.5 & 269 & 29.6 & 260 & 28.6 & 235 & 25.9 & \\
\hline Male & 111 & 39.5 & 80 & 28.5 & 61 & 21.7 & 50 & 17.8 & \\
\hline Non-cisgender & 39 & 73.6 & 11 & 20.8 & 18 & 34.0 & 21 & 39.6 & \\
\hline Student Status & & & & & & & & & $<.01$ \\
\hline Undergraduate & 426 & 60.7 & 178 & 25.4 & 223 & 31.8 & 203 & 28.9 & \\
\hline $\begin{array}{l}\text { Graduate/ } \\
\text { Professional }\end{array}$ & 212 & 40.0 & 178 & 33.6 & 112 & 21.1 & 100 & 18.9 & \\
\hline Race/Ethnicity & & & & & & & & & 0.13 \\
\hline $\begin{array}{l}\text { American } \\
\text { Indian/ Alaskan } \\
\text { Native }\end{array}$ & 33 & 55.0 & 19 & 31.7 & 17 & 28.3 & 16 & 26.7 & \\
\hline Asian & 37 & 37.4 & 32 & 32.3 & 20 & 20.2 & 17 & 17.2 & \\
\hline $\begin{array}{l}\text { Black/African } \\
\text { American }\end{array}$ & 15 & 55.6 & 6 & 22.2 & 7 & 25.9 & 8 & 29.6 & \\
\hline Hispanic/Latino & 138 & 57.7 & 70 & 29.3 & 69 & 28.9 & 69 & 28.9 & \\
\hline White & 376 & 51.4 & 207 & 28.3 & 202 & 27.6 & 174 & 23.8 & \\
\hline
\end{tabular}

${ }^{a}$ Chi-square test for difference in prevalence of anxiety severity (no anxiety, mild anxiety, moderate anxiety, severe anxiety) within demographic groups; $p<0.05$ indicates statistical significance 


\begin{tabular}{|c|c|c|c|c|c|c|c|c|}
\hline \multirow[b]{2}{*}{$>1$ Race/Other } & \multicolumn{2}{|c|}{$\begin{array}{l}\text { Anxiety } \\
\text { (GAD-7 } \geq \\
\text { 10) }\end{array}$} & \multicolumn{2}{|c|}{$\begin{array}{l}\text { Mild Anxiety } \\
\text { (GAD-7 score } \\
5-9)\end{array}$} & \multicolumn{2}{|c|}{$\begin{array}{l}\text { Moderate Anxiety } \\
\text { (GAD-7 score 10- } \\
\text { 14) }\end{array}$} & \multicolumn{2}{|c|}{$\begin{array}{l}\text { Severe Anxiety } \\
\text { (GAD-7 score } \geq \\
15 \text { ) }\end{array}$} \\
\hline & 44 & 55.7 & 22 & 27.9 & 24 & 30.4 & 20 & 25.3 \\
\hline
\end{tabular}

Undergraduate students had a significantly higher prevalence of GAD-7 scores indicating anxiety (60.7\%) compared to graduate students $(40.0 \%)(p<0.01)$. While anxiety severity was not significantly different by race/ethnicity $(p=0.13)$, Asian participants had the lowest prevalence of anxiety $(37.4 \%)$ compared to all other race/ethnicity groups (>50\%). Hispanic/Latino participants had the highest prevalence of anxiety $(57.7 \%)$, followed by students reporting other or more than one race/ethnicity $(55.7 \%)$. The prevalence of severe anxiety, however, was highest in Black/African American students (29.6\%), followed by Hispanic/Latino students (28.9\%). 
Table 3

Mean AEBQ scores in participants by anxiety status

\begin{tabular}{|c|c|c|c|c|c|c|c|}
\hline \multirow[b]{2}{*}{ AEBQ Indicators } & \multicolumn{2}{|c|}{$\begin{array}{l}\text { All Participants }(n= \\
\text { 1243) }\end{array}$} & \multicolumn{2}{|c|}{$\begin{array}{l}\text { No Anxiety }(n= \\
598)\end{array}$} & \multicolumn{2}{|c|}{$\begin{array}{l}\text { Anxiety* }(n= \\
645)\end{array}$} & \multirow[b]{2}{*}{$p^{\mathrm{a}}$} \\
\hline & Mean & SD & Mean & SD & Mean & SD & \\
\hline \multicolumn{8}{|l|}{$\begin{array}{l}\text { Food approach } \\
\text { subscales }\end{array}$} \\
\hline Hunger & 3.10 & 0.75 & 2.98 & 0.74 & 3.21 & 0.75 & $<.01$ \\
\hline Food responsiveness & 3.18 & 0.75 & 3.08 & 0.73 & 3.27 & 0.75 & $<.01$ \\
\hline Emotional over-eating & 2.85 & 1.01 & 2.69 & 0.93 & 2.99 & 1.05 & $<.01$ \\
\hline Enjoyment of food & 4.14 & 0.80 & 4.24 & 0.71 & 4.04 & 0.86 & $<.01$ \\
\hline \multicolumn{8}{|l|}{$\begin{array}{l}\text { Food avoidance } \\
\text { subscales }\end{array}$} \\
\hline Satiety responsiveness & 2.74 & 0.82 & 2.66 & 0.77 & 2.81 & 0.86 & $<.01$ \\
\hline Emotional under-eating & 3.11 & 0.96 & 3.03 & 0.89 & 3.18 & 1.02 & $<.01$ \\
\hline Food fussiness & 2.03 & 0.84 & 1.95 & 0.79 & 2.11 & 0.88 & $\begin{array}{l}< \\
0.01\end{array}$ \\
\hline Slowness in eating & 2.71 & 1.01 & 2.66 & 0.94 & 2.75 & 1.06 & 0.23 \\
\hline
\end{tabular}

Table 3 shows mean AEBQ subscale scores in the full sample and by anxiety status. Subscale scores were not normally distributed $(p<0.05)$. Mean scores for food approach subscales (hunger, food responsiveness, emotional over-eating) were significantly higher in those with anxiety, except enjoyment of food which was significantly lower $(p<0.01)$. Mean scores for three of four food avoidance subscales (satiety responsiveness, emotional under-eating, and food fussiness) were significantly higher in those with anxiety compared to those without anxiety $(p<0.01)$. 
Table 4

Unadjusted and adjusted associations between GAD-7 score and AEBQ indicators

\begin{tabular}{|c|c|c|c|c|}
\hline \multirow[b]{2}{*}{ AEBQ Indicators } & \multicolumn{2}{|c|}{ GAD-7 score correlation ${ }^{a}$} & \multicolumn{2}{|c|}{ Multivariate Regression ${ }^{b}$} \\
\hline & r-square & $p$ & $\beta$ & $p$ \\
\hline \multicolumn{5}{|l|}{ Food approach subscales } \\
\hline Hunger & 0.24 & $<0.01$ & 0.027 & $<0.01$ \\
\hline Food responsiveness & 0.14 & $<0.01$ & 0.014 & $<0.01$ \\
\hline Emotional over-eating & 0.18 & $<0.01$ & 0.034 & $<0.01$ \\
\hline Enjoyment of food & -0.11 & $<0.01$ & -0.014 & $<0.01$ \\
\hline \multicolumn{5}{|c|}{ Food avoidance subscales } \\
\hline Satiety responsiveness & 0.13 & $<0.01$ & 0.012 & $<0.01$ \\
\hline Emotional under-eating & 0.07 & 0.01 & 0.003 & 0.50 \\
\hline Food fussiness & 0.08 & $<0.01$ & 0.011 & 0.01 \\
\hline Slowness in eating & 0.03 & 0.29 & 0.000 & 0.07 \\
\hline
\end{tabular}

In the full sample, seven of the eight AEBQ indicators were significantly correlated with GAD-7 score based on Spearman's correlation coefficients (Table 4). Six of the eight indicators were positively correlated with GAD-7 score; hunger and emotional over-eating had the strongest correlations ( $r$-square = 0.24 and 0.18 , respectively; $p<0.01)$. Enjoyment of food was significantly negatively correlated with GAD7 score (r-square $=-0.11 ; p<0.01)$ and slowness in eating was not correlated with GAD-7 score $(p=0.29)$. In multivariate linear regression adjusting for age, gender, race/ethnicity, and student status, associations between GAD-7 score and AEBQ indicators remained significant, except for emotional under-eating $(p=$ $0.50)$ and slowness in eating $(p=0.07)$.

\section{Discussion}

Over half of undergraduate and graduate/professional students at a large University in the southwest United States experienced moderate to severe anxiety in fall 2020 amidst the COVID-19 pandemic. The prevalence of anxiety in this study was much higher than estimates from spring 2020 which ranged from $25-43 \%$ in college students around the world $(8,11)$. While all demographic groups in this study experienced anxiety, estimates of moderate and severe anxiety were most worrisome in younger participants 18-20 years of age, non-cisgender participants, and undergraduate students compared to graduate/professional students. As the COVID-19 pandemic lingers, a global mental health crisis is 
hypothesized (29) and, based on mounting evidence, may disproportionately affect young adults including university students (3).

This study suggests anxiety is associated with eating attitudes and behaviors. All eating behaviors except slowness in eating differed significantly between participants experiencing anxiety and those not experiencing anxiety. Participants with anxiety had higher scores for food approach and food avoidant behaviors than those not experiencing anxiety, except enjoyment of eating which was significantly lower $(p<0.01)$. Moreover, participants with anxiety in this study had higher mean scores for emotional overeating, emotional under-eating, and hunger compared to a study examining the AEBQ in the general population in Australia and the United Kingdom prior to the COVID-19 pandemic (26). Another study of Greek and Spanish adults conducted in April 2020 during the COVID-19 pandemic also found high scores for inappropriate eating behaviors including restraint eating, external eating, and emotional eating (30). All three behaviors were significantly associated with GAD-7 score in this study suggesting a link between anxiety and eating behaviors during COVID-19.

Individuals experiencing anxiety may either turn to food or avoid food as coping mechanisms since both food approach and food avoidance behaviors were significantly higher in participants with anxiety. Previously published evidence also suggests both emotional over-eating and emotional under-eating are responses to anxiety (31). Attempting to manage anxiety through undesirable eating behaviors may be even more pronounced due to the additional stress and worry of the COVID-19 pandemic. Evidence also suggests a bi-directional relationship between anxiety and eating behaviors. While anxiety could lead to undesirable eating patterns, it could very well be that undesirable or disordered eating behaviors induce anxiety (32). Additional longitudinal research in healthy individuals and those with diagnosed eating disorders must address the cause and effect of anxiety and eating behaviors to help inform prevention and treatment.

In this study, GAD-7 scores were strongly associated with most AEBQ subscales. Particularly concerning is the positive correlation between GAD-7 score and hunger indicating increasing anxiety severity is associated with increasing hunger. In addition, the positive correlation between GAD-7 score and emotional over-eating indicates increasing anxiety severity is associated with increasing over-eating behaviors. Finally, the positive correlation between GAD-7 score and food responsiveness indicates increasing anxiety severity is associated with increased tendency to eat more in response to food cues, potentially in excess of requirements. These associations remained directional and significant after adjusting for age, gender, race/ethnicity, and student status. A similar study conducted during the COVID19 pandemic also suggests GAD-7 score is significantly correlated with Dutch Eating Behavior Questionnaire (DBEQ) scales including restrained eating, emotional eating, and external eating (30). In light of the pandemic, undesirable eating behaviors may be even more exacerbated and, coupled with media-driven concepts like the "quarantine 15", may increase the risk for clinical eating disorders (22). Hunger and emotional over-eating, for example, are predominant symptoms of anorexia nervosa and binge eating disorder. Additional research is needed to examine specific relationships between AEBQ subscales and risk for clinical eating disorders. 


\section{Limitations}

Limitations must be considered when interpreting results of this study. All data were self-reported and certain demographic groups (females, white participants, and undergraduate students) were overrepresented. Data were also missing for demographic questions including 45 missing responses for age. In addition, data were collected during the second wave of the COVID-19 pandemic in fall 2020 which almost certainly influenced experienced anxiety and potentially its relationship with eating behaviors and attitudes. Finally, given the cross-sectional design of the study, it is impossible to determine if anxiety led to undesirable eating behaviors or if those with undesirable eating behaviors were more likely to experience anxiety. The directionality of the relationship between anxiety and eating behaviors, particularly hunger, emotional over-eating, emotional under-eating, and food responsiveness must be explored in future studies.

\section{Conclusions}

In a large sample of undergraduate and graduate/professional students in the United States, the prevalence of anxiety during the COVID-19 pandemic suggests a mental health crisis, particularly in younger undergraduate students and those who identify as a gender other than male or female. University students experiencing anxiety reported higher degrees of undesirable eating behaviors including hunger, food responsiveness, emotional over-eating and under-eating, food fussiness, and less enjoyment of food than those with no anxiety. Anxiety severity is also strongly positively associated with hunger, emotional over-eating, and food responsiveness.

As health professionals prepare to tackle the mental health crisis left in the wake of the COVID-19 pandemic, relationships between anxiety and eating behaviors in university students and the general population should be considered. University students with moderate to severe anxiety may experience undesirable attitudes and behaviors toward eating, potentially increasing the risk of eating disorders.

\section{Abbreviations}

COVID-19: Coronavirus disease 2019

CDC: Centers for Disease Control and Prevention

STROBE-nut: Strengthening the Reporting of Observational Studies in Epidemiology -

Nutritional Epidemiology

GAD-7: Generalized Anxiety Disorder Scale

AEBQ: Adult Eating Behavior Questionnaire

SAS: Statistical Analysis Software 
DEBQ: Dutch Eating Behavior Questionnaire

\section{Declarations}

\section{Ethics approval and consent to participate:}

This study received approval from the University of New Mexico Institutional Review Board (Reference number: 1522923). Documentation of informed consent was waived for this study.

\section{Consent for publication:}

Not applicable.

\section{Availability of data and materials:}

The dataset analyzed during the current study is available from the corresponding author on reasonable request.

\section{Competing interests:}

The authors declare that they have no competing interests.

\section{Funding:}

No funding was obtained for this research.

\section{Authors' contributions:}

Kathryn E Coakley collected and interpreted data and was the major contributor in writing the manuscript. Huyen Le, Spirit Rae Silva, and Aspen Wilks designed the survey and assisted with editing the manuscript. All authors read and approved the final manuscript.

\section{Acknowledgements:}

The authors would like to acknowledge the Dean's Office in each University College and the Graduate and Professional Student Association who assisted in distributing the survey.

\section{References}

1. Torales J, O'Higgins M, Castaldelli-Maia JM, Ventriglio A. The outbreak of COVID-19 coronavirus and its impact on global mental health. Int J Soc Psychiatry. 2020;66(4):317-20.

2. Flanagan EW, Beyl RA, Fearnbach SN, Altazan AD, Martin CK, Redman LM. The impact of COVID-19 stay-at-home orders on health behaviors in adults. Obesity (Silver Spring). 2020. 
3. Czeisler M, Lane RI, Petrosky E, Wiley JF, Christensen A, Njai R, et al. Mental Health, Substance Use, and Suicidal Ideation During the COVID-19 Pandemic - United States, June 24-30, 2020. MMWR Morb Mortal Wkly Rep. 2020;69(32):1049-57.

4. Anxiety: Facts \& Statistics. Anxiety and Depression Association of American (ADAA): Anxiety and Depression Association of American (ADAA); 2020. Available from: https://adaa.org/aboutadaa/press-room/facts-statistics.

5. Xiong J, Lipsitz O, Nasri F, Lui LMW, Gill H, Phan L, et al. Impact of COVID-19 pandemic on mental health in the general population: A systematic review. J Affect Disord. 2020;277:55-64.

6. Gillis A, Krull L. COVID-19 Remote Learning Transition in Spring 2020: Class Structures, Student Perceptions, and Inequality in College Courses. Teaching Sociology. 2020;48(4):283-99.

7. Biber DD, Melton B, Czech DR. The impact of COVID-19 on college anxiety, optimism, gratitude, and course satisfaction. J Am Coll Health. 2020:1-6.

8. Cao W, Fang Z, Hou G, Han M, Xu X, Dong J, et al. The psychological impact of the COVID-19 epidemic on college students in China. Psychiatry Res. 2020;287:112934.

9. Wathelet M, Duhem S, Vaiva G, Baubet T, Habran E, Veerapa E, et al. Factors Associated With Mental Health Disorders Among University Students in France Confined During the COVID-19 Pandemic. JAMA Netw Open. 2020;3(10):e2025591.

10. Wang X, Hegde S, Son C, Keller B, Smith A, Sasangohar F. Investigating Mental Health of US College Students During the COVID-19 Pandemic: Cross-Sectional Survey Study. J Med Internet Res. 2020;22(9):e22817.

11. Islam MA, Barna SD, Raihan H, Khan MNA, Hossain MT. Depression and anxiety among university students during the COVID-19 pandemic in Bangladesh: A web-based cross-sectional survey. PLoS One. 2020;15(8):e0238162.

12. Son C, Hegde S, Smith A, Wang X, Sasangohar F. Effects of COVID-19 on College Students' Mental Health in the United States: Interview Survey Study. J Med Internet Res. 2020;22(9):e21279.

13. Yau YH, Potenza MN. Stress and eating behaviors. Minerva Endocrinol. 2013;38(3):255-67.

14. Cheng MY, Wang SM, Lam YY, Luk HT, Man YC, Lin CY. The Relationships Between Weight Bias, Perceived Weight Stigma, Eating Behavior, and Psychological Distress Among Undergraduate Students in Hong Kong. J Nerv Ment Dis. 2018;206(9):705-10.

15. Garcia SC, Mikhail ME, Keel PK, Burt SA, Neale MC, Boker S, et al. Increased rates of eating disorders and their symptoms in women with major depressive disorder and anxiety disorders. Int J Eat Disord. 2020.

16. Keck MM, Vivier H, Cassisi JE, Dvorak RD, Dunn ME, Neer SM, et al. Examining the Role of Anxiety and Depression in Dietary Choices among College Students. Nutrients. 2020;12(7).

17. Wattick RA, Hagedorn RL, Olfert MD. Relationship between Diet and Mental Health in a Young Adult Appalachian College Population. Nutrients. 2018;10(8). 
18. Eisenberg D, Nicklett EJ, Roeder K, Kirz NE. Eating disorder symptoms among college students: prevalence, persistence, correlates, and treatment-seeking. J Am Coll Health. 2011;59(8):700-7.

19. de Matos AP, Rodrigues PRM, Fonseca LB, Ferreira MG, Muraro AP. Prevalence of disordered eating behaviors and associated factors in Brazilian university students. Nutr Health. 2020:260106020971136.

20. Pengpid S, Peltzer K. Risk of disordered eating attitudes and its relation to mental health among university students in ASEAN. Eat Weight Disord. 2018;23(3):349-55.

21. Termorshuizen JD, Watson HJ, Thornton LM, Borg S, Flatt RE, MacDermod CM, et al. Early impact of COVID-19 on individuals with self-reported eating disorders: A survey of $\sim 1,000$ individuals in the United States and the Netherlands. Int J Eat Disord. 2020;53(11):1780-90.

22. Keel PK, Gomez MM, Harris L, Kennedy GA, Ribeiro J, Joiner TE. Gaining "The Quarantine 15:" Perceived versus observed weight changes in college students in the wake of COVID-19. Int J Eat Disord. 2020;53(11):1801-8.

23. Lachat C, Hawwash D, Ocké MC, Berg C, Forsum E, Hörnell A, et al. Strengthening the Reporting of Observational Studies in Epidemiology-Nutritional Epidemiology (STROBE-nut): An Extension of the STROBE Statement. PLoS Med. 2016;13(6):e1002036.

24. Löwe B, Decker O, Müller S, Brähler E, Schellberg D, Herzog W, et al. Validation and standardization of the Generalized Anxiety Disorder Screener (GAD-7) in the general population. Med Care. 2008;46(3):266-74.

25. Spitzer RL, Kroenke K, Williams JB, Löwe B. A brief measure for assessing generalized anxiety disorder: the GAD-7. Arch Intern Med. 2006;166(10):1092-7.

26. Mallan KM, Fildes A, de la Piedad Garcia X, Drzezdzon J, Sampson M, Llewellyn C. Appetitive traits associated with higher and lower body mass index: evaluating the validity of the adult eating behaviour questionnaire in an Australian sample. Int J Behav Nutr Phys Act. 2017;14(1):130.

27. Hunot C, Fildes A, Croker H, Llewellyn $\mathrm{CH}$, Wardle J, Beeken RJ. Appetitive traits and relationships with BMI in adults: Development of the Adult Eating Behaviour Questionnaire. Appetite. 2016;105:356-63.

28. Hunot-Alexander C, Beeken RJ, Goodman W, Fildes A, Croker H, Llewellyn C, et al. Confirmation of the Factor Structure and Reliability of the 'Adult Eating Behavior Questionnaire' in an Adolescent Sample. Front Psychol. 2019;10:1991.

29. Izaguirre-Torres D, Siche R. Covid-19 disease will cause a global catastrophe in terms of mental health: A hypothesis. Med Hypotheses. 2020;143:109846.

30. Papandreou C, Arija V, Aretouli E, Tsilidis KK, Bulló M. Comparing eating behaviours, and symptoms of depression and anxiety between Spain and Greece during the COVID-19 outbreak: Cross-sectional analysis of two different confinement strategies. Eur Eat Disord Rev. 2020;28(6):836-46.

31. Constant A, Gautier Y, Coquery N, Thibault R, Moirand R, Val-Laillet D. Emotional overeating is common and negatively associated with alcohol use in normal-weight female university students. Appetite. 2018;129:186-91. 
32. Puccio F, Fuller-Tyszkiewicz M, Youssef G, Mitchell S, Byrne M, Allen N, et al. Longitudinal Bidirectional Effects of Disordered Eating, Depression and Anxiety. Eur Eat Disord Rev. 2017;25(5):3518.

\section{Supplementary Files}

This is a list of supplementary files associated with this preprint. Click to download.

- STROBEnutchecklisttable.docx 